\title{
Low-temperature stabilization of pure MnO
}

\author{
K S NANJUNDASWAMY and M N SANKARSHANAMURTHY* \\ Materials Research Laboratory, Indian Institute of Science, Bangalore 560012, India \\ MS received 24 May 1985
}

\begin{abstract}
A technique has been worked out for stabilizing polycrystalline $\mathrm{MrO}$ against oxidation in air without dopants and without exceeding a temperature of $800^{\circ} \mathrm{C}$ in the process. The material is active though highly resistant to oxidation.
\end{abstract}

Keywords. Stabilized $\mathrm{MnO}$; active $\mathrm{MnO}$; pure $\mathrm{MnO}$.

\section{Introduction}

$\mathrm{MnO}$, the lowest oxide of manganese, is well known, in a polycrystalline form, to pick up oxygen from air and get oxidized easily even at room temperature. The oxide can however be dead burnt by heating at $1000^{\circ} \mathrm{C}$ for some hours in an inert atmosphere or hydrogen and thereby stabilized against oxidation at room temperature (Hay et al 1934; Cheetham and Hope 1983). The stabilization of $\mathrm{MnO}$ by processing below $800^{\circ} \mathrm{C}$ has also been achieved by doping with other oxides, particularly $\mathrm{ZnO}$ (Deshpande et al 1978; Deshpande and Murthy 1981). A low-temperature stabilization of MnO without any dopants does not appear to have been worked out so far. The low-temperature of processing is necessary to keep the oxide active enough for purposes of catalysis and solid state reaction with other oxides; the absence of dopants is obviously necessary to avoid unwanted impurities. The present paper deals with the stabilization of pure polycrystalline $\mathrm{MnO}$ by processing below $800^{\circ} \mathrm{C}$ and maintaining the oxide in a finely divided state.

\section{Experimental}

The experimental set up is illustrated in figure 1 which is a somewhat simplified version of that described in an earlier paper by one of the present authors (Deshpande and Murthy 1981). The system is perfectly gas-tight and previously tested for holding vacuum, though evacuation is not needed in this work. The figure is self-explanatory. A higher oxide of manganese prepared by heating precipitated manganous oxalate at $300^{\circ} \mathrm{C}$ in air is taken in platinum boat, 5 , while an excess of reduced iron powder is taken in silica boats, 4 , placed in the furnace tube in the vicinity of the platinum boat. It is assumed that the iron gets converted to $\mathrm{Fe}_{3} \mathrm{O}_{4}$ with the available oxygen in the higher oxide of manganese taken, and double the amount of iron calculated on this basis is

* To whom all correspondence should be addressed 


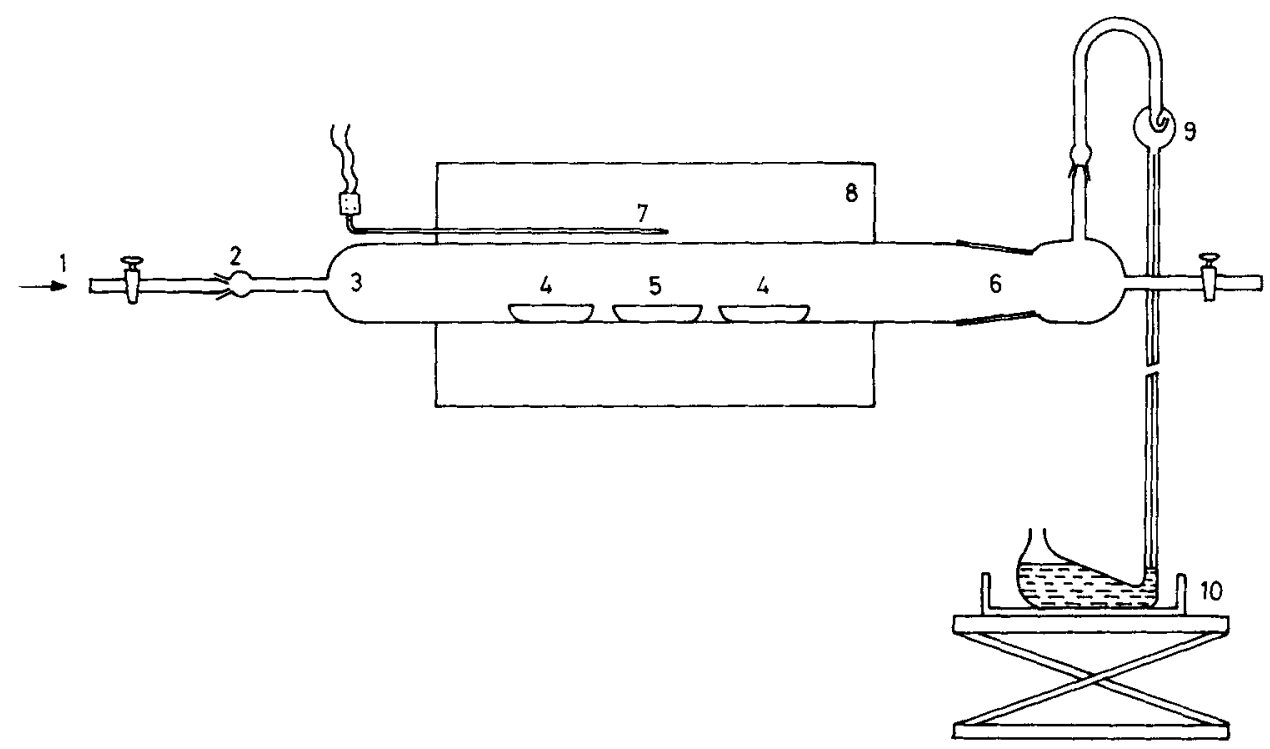

Figure 1. Preparation unit for MnO: (1) gas inlet; (2) B-14 silica to pyrex joint; (3) quartz tube ( $50 \mathrm{~mm}$ dia); (4) iron powder in Silica boats; (5) $\mathrm{Mn}_{2} \mathrm{O}_{3}$ in platinum boat; (6) B-55 silica to pyrex joint; (7) thermocouple; (8) Kanthal-wound furnace; (9) mercury manometer/cut off; (10) petri-dish with foam rubber cushion.

taken in the silica boats. Care is taken to avoid any contamination of the oxide of manganese with the iron. It helps to dilute the iron powder a little with an inert material such as alumina to avoid the formation of iron clusters on heating. The unit is then assembled as shown in the figure and flushed with cylinder nitrogen for 10-15 minutes with the gas entering at 1 and bubbling out of the manometer 9 . The inlet stopcock is then closed, the temperature of the reaction tube is raised to $750-800^{\circ} \mathrm{C}$ and the oxide of manganese is soaked at this temperature for about eight hours in a static atmosphere of cylinder nitrogen with the reduced iron also present in the system. The furnace is then switched off and cooled to room temperature. The resulting oxide of manganese in the platinum boat is taken out by opening ground joint 6 .

An $\mathrm{x}$-ray powder pattern of the material completely tallied with that of $\mathrm{MnO}$. The oxide of manganese was checked for any active available oxygen by heating it with hydrochloric acid in a current of oxygen-free nitrogen (Schenk 1963), and in a closed system previously flushed thoroughly with the same gas. The gas was allowed to bubble through a solution of potassium iodide and starch in the same closed system. The starch iodide showed no change of colour indicating the absence of $\mathrm{Mn}^{3+}$. An X-ray photoelectron spectrum (XPS) of the oxide of manganese gave the expected peaks at 640.9 and $652.5 \mathrm{eV}$ corresponding to $2 p_{3 / 2}$ and $2 p_{1 / 2}$ core levels of $\mathrm{Mn}^{2+}$. The peaks at 641.7 and $653.3 \mathrm{eV}$, characteristic of the same core levels of $\mathrm{Mn}^{3+}$, were particularly looked for and found to be absent (Rao et al 1979); in fact, there were no other peaks. A known weight of this oxide of manganese was heated overnight in a muffle furnace at $900^{\circ} \mathrm{C}$, cooled in a desiccator and weighed. The increase in weight corresponded to $7.52 \%$ which was just the expected value for oxidation of $\mathrm{MnO}$ to $\mathrm{Mn}_{3} \mathrm{O}_{4}$. A thermogram of this oxide of manganese with a heating rate of $10^{\circ} / \mathrm{min}$ showed an increase in weight only after $440^{\circ} \mathrm{C}$. When, however, the thermogram was 
repeated with a slower heating rate of $3^{\circ} / \mathrm{min}$, there was a faintly perceptible gain in weight only above $200^{\circ} \mathrm{C}$, though even then the increase in weight upto $400^{\circ} \mathrm{C}$ was less than $0.5 \%$. A diffuse reflectance spectrum of the substance gave absorption peaks at 616,485 and $422 \mathrm{~nm}$ in complete accord with the absorption spectrum of $\mathrm{MnO}$ single crystals reported earlier (Pratt and Coelho 1959). A scanning electron micrograph of this $\mathrm{MnO}$ is given in figure 2. Every one of the properties of $\mathrm{MnO}$ given above was rechecked after storing the powder in air without any special precautions for three months, and found to be fully reproducible.

The $\mathrm{MnO}$ prepared as above was mixed with a little $\mathrm{NH}_{4} \mathrm{HCO}_{3}$ and heated on a water bath side by side with another sample of the same $\mathrm{MnO}$ unmixed with $\mathbf{N H}_{4} \mathrm{HCO}_{3}$. It was found that as soon as the bicarbonate started decomposing, the $\mathrm{MnO}$ mixed with it got oxidized and turned black; while the $\mathrm{MnO}$ without $\mathrm{NH}_{4} \mathrm{HCO}_{3}$ remained olive green as before and answered no test for $\mathrm{Mn}^{3+}$.

\section{Discussion}

The reduced iron powder acts as an oxygen getter and completely takes up the available oxygen in the higher oxide of manganese as well as the cylinder nitrogen initially filling the reaction tube. Whatever oxide of iron is formed in the process is incapable of reoxidizing the $\mathrm{MnO}$; and this is as it should be since it is well known that while $\mathrm{Fe}^{2+}$ can reduce $\mathrm{Mn}^{3+}, \mathrm{Mn}^{2+}$ is never known to reduce $\mathrm{Fe}^{3+}$. The chemical test for the absence of available oxygen, the expected weight increase in air at $900^{\circ} \mathrm{C}$ to $\mathrm{Mn}_{3} \mathrm{O}_{4}$, the $\mathrm{XPS}$, the $\mathrm{x}$-ray powder pattern and the diffuse optical reflectance spectrum confirm the formation of $\mathrm{MnO}$ and the absence of $\mathrm{Mn}^{3+}$ in it. The fact that the substance could stand all these tests after a lapse of three months of storage in air shows the excellent keeping qualities of this $\mathrm{MnO}$. The thermograms show that this $\mathrm{MnO}$ is not oxidized in

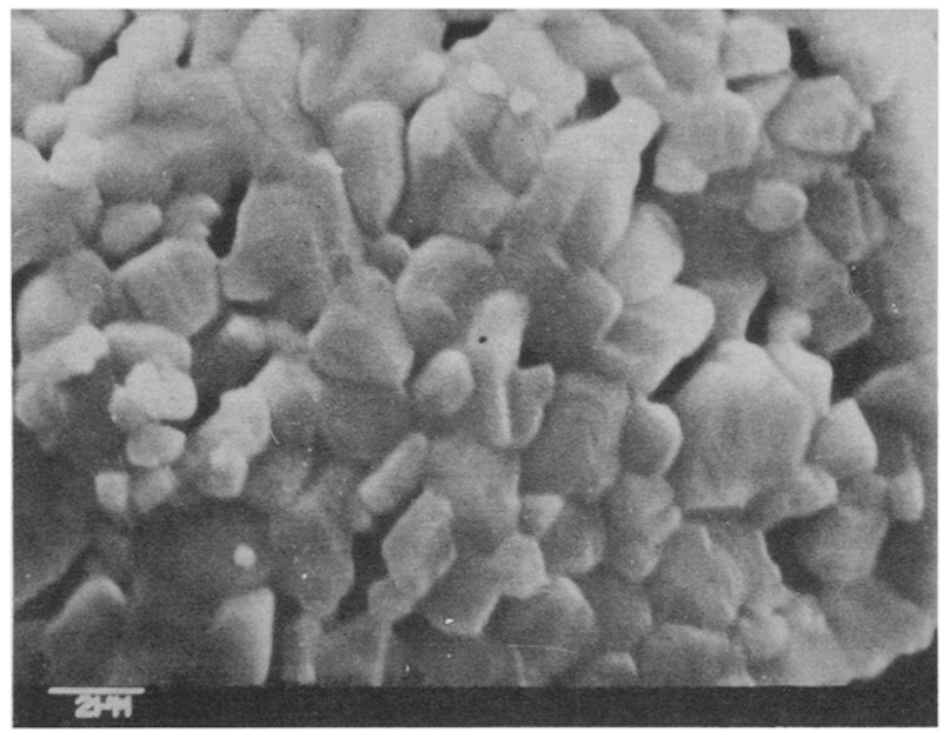

Figure 2. Scanning electron micrograph of $\mathrm{MnO}$. 
air upto $200^{\circ} \mathrm{C}$ while its oxidation even upto $400^{\circ} \mathrm{C}$ is very slow. The electron micrograph (figure 2 ) shows fairly uniform particles in the range of $2-4 \mu \mathrm{m}$. The escape of available oxygen from and through the higher oxide of manganese during the preparation breaks up the particles which are already small and active, being prepared by an effervescent decomposition of manganous oxalate in air below $300^{\circ} \mathrm{C}$. Since the subsequent processing is carried out below $800^{\circ} \mathrm{C}$, the grains are naturally as fine as figure 2 indicates. It is well known that the oxidation of $\mathrm{MnO}$ in air is nucleated and triggered off at a limited number of active sites at which an initial highly exothermic chemisorption of oxygen occurs (Hayward and Trapnell 1964). Apparently such highly active sites disappear in the process of soaking at 750 to $800^{\circ} \mathrm{C}$ for some hours, thereby conferring on the $\mathrm{MnO}$ the observed resistance to oxidation. All the same, the particles are still finely divided as mentioned earlier. The fact that this $\mathrm{MnO}$ loses its resistance to oxidation by the effervescent decomposition of $\mathrm{NH}_{4} \mathrm{HCO}_{3}$ mixed with it clearly confirms the above explanation of its observed stability. The gases $\left(\mathrm{NH}_{3}, \mathrm{CO}_{2}\right.$ and $\mathrm{H}_{2} \mathrm{O}$ ) evolved from the decomposing bicarbonate disintegrate the $\mathrm{MnO}$ particles and expose fresh active sites at which chemisorption of oxygen can initiate the oxidation of $\mathrm{MnO}$. Incidentally this gives a method of improving the activity of this $\mathrm{MnO}$ in situ provided the ambient atmosphere is inert.

This method of stabilizing $\mathrm{MnO}$ has obvious advantages over that of 'dead burning' above $1000^{\circ} \mathrm{C}$, or doping with other oxides such as $\mathrm{ZnO}$ (Hay et al 1934; Deshpande et al 1978; Deshpande and Murthy 1981). The former process renders the MnO too inactive for any subsequent use while the latter introduces unwanted and sometimes harmful impurities besides being more cumbersome and difficult. In detail, the latter process (which was also worked out by one of the present authors, MNSM) involves an initial evacuation of the system, filling the system with oxygen-free nitrogen, maintaining a running current of the inert gas (scrupulously free from oxygen) all through the thermal decomposition of the oxalates and above all, thoroughly degassing the $\mathrm{MnO}$ in running high-vacuum in order to desorb the $\mathrm{CO}$ produced by the decomposition of the oxalates and tenaciously chemisorbed by the $\mathrm{MnO}$ (Hayward and Trapnell 1964). The heat of chemisorption of $\mathrm{CO}$ on $\mathrm{MnO}$ is as high as $64.4 \mathrm{kcal}$ per mole at room temperature. The continuous flushing of the system in this process with oxygen-free nitrogen is necessitated by the tendency of the $\mathrm{CO}_{2}$ evolved in the process to oxidize the $\mathrm{MnO}$ at the temperature of preparation (Sidgwick 1950). The degassing needed in the process is liable to remove part of the thermolabile $\mathrm{ZnO}$ and thereby change the stoichiometry of the solid solution arbitrarily. Furthermore, traces of $\mathrm{CO}$ may still remain with the $\mathrm{MnO}$ and this may be undesirable if the $\mathrm{MnO}$ has to be employed subsequently in the preparation of mixed oxide systems involving easily reducible metal oxides such as $\mathrm{NiO}, \mathrm{Fe}_{2} \mathrm{O}_{3}, \mathrm{CuO}, \mathrm{CoO}$ etc. The present process has none of these complications, involving no evacuation at any stage, employing only cylinder nitrogen (that too only during the initial flushing of the system) and requiring no degassing. Obviously, there is no possibility of any CO coming into the picture at any stage of this process.

\section{Conclusion}

The present paper deals with a novel method of stabilizing pure polycrystalline $\mathrm{MnO}$ employing a process not exceeding a temperature of $800^{\circ} \mathrm{C}$. The $\mathrm{MnO}$ is surprisingly 
resistant to oxidation in air while being sufficiently finely divided with particle sizes in the range of $2-4 \mu \mathrm{m}$. The particle size can be further reduced if necessary by heating in situ with $\mathrm{NH}_{4} \mathrm{HCO}_{3}$ in an inert atmosphere or in vacuum below $100^{\circ} \mathrm{C}$. The process is very simple and gives an $\mathrm{MnO}$ totally free from harmful adsorbed gases.

While $\mathrm{MnO}$ chemisorbs carbon monoxide, oxygen and hydrogen very well (Hayward and Trapnell 1964), it has unfortunately not been used as a contact catalyst in reactions involving such gases. The reason is obviously that it has not been available in a stable and sufficiently active form. Many mixed oxide compositions and electronic ceramics - especially the technically very important professional soft ferrites which are actually manganous zinc ferrous ferrites-need pure $\mathrm{MnO}$, without any $\mathrm{Mn}^{3+}$, in a sufficiently active form to react efficiently with other oxides. The $\mathrm{MnO}$ made as described in this paper should prove useful for all such purposes.

\section{Acknowledgements}

Thanks are due to Dr M S Hegde for helping us with XPS, Dr K C Patil for taking thermograms and Dr T S Panchapagesan for SEM pictures. The authors are very grateful to Prof C N R Rao and Prof K J Rao for their kind encouragement.

\section{References}

Cheetham A K and Hope D A O 1983 Phys. Rev. B27 6964

Deshpande C E, Pant L M and Murthy M N S 1978 Indian J. Chem. A16 251

Deshpande C E and Murthy M N S 1981 Bull. Mater. Sci. 3261

Hay R, Howat D D and White J $1934 J$ West Scotland, Iron Steel Inst. 4197

Hayward D O and Trapnell B M W 1964 Chemisorption (London: Butterworths) p. 85

Rao C N R, Sarma D D, Vasudevan S and Hegde M S 1979 Proc. R. Soc. London A367 239

Pratt G W and Coelho R 1959 Phys. Rev. 116 281, 282

Schenk P W 1963 in Hand book of preparative inorganic chemistry 2nd ed., (ed.) G Brauer (transl. ed.) R F Riley (New York: Academic Press) vol. 1, p. 458

Sidgwick N V 1950 The chemical elements and their compounds (Oxford: Clarendon Press) vol. 2, p. 1284 